\title{
Is the right testis more affected by cryptorchidism than the left testis? An ultrasonographic approach in dogs of different sizes and breeds
}

\author{
V.G.S. Tannouz', M.J. Mamprim², M.D. Lopes², C.A. Santos-Sousa ${ }^{3}$, P. Souza Junior ${ }^{4}$, \\ M.A. Babinski ${ }^{5}$, M. Abidu-Figueiredo ${ }^{6}$
}

${ }^{1}$ Autonomous Veterinarian, Centre for Veterinarian Diagnosis and Support (Centro de Apoio e Diagnóstico Veterinário - $(A D)$, Rio de Janeiro, Brazil

2Veterinarian Radiology and Animal Reproduction Department, School of Veterinary Medicine and Animal Science,

UNESP, Botucatu, São Paulo, Brazil

${ }^{3}$ Federal University of Acre, Brazil

${ }^{4}$ Federal University of Pampa, Uruguaiana, Brazil

${ }^{5}$ Morphology Department, Fluminense Federal University, Rio de Janeiro, Brazil

${ }^{6}$ Human and Animal Anatomy Department, Rural Federal University of Rio de Janeiro, Brazil

[Received: 22 January 2019; Accepted: 9 February 2019]

Background: Considered the most common congenital testicular abnormality of companion animals and a predisposition factor to the development of testicular neoplasia, cryptorchidism is defined as the non-descent of one or both testes to their normal anatomical location. Data on the occurrence of cryptorchidism in Brazil are scarce. The purpose of this work was to verify the occurrence of cryptorchidism in dogs of different sizes and breeds.

Materials and methods: Cryptorchidism identification was carried out by ultrasound scanning, from November, 1994 to March, 2007, at the Centre for Veterinarian Diagnosis and Support (Centro de Apoio e Diagnóstico Veterinário - (AD), in Rio de Janeiro. 4924 male dogs of different breeds were examined, revealing 403 (8.2\%) cryptorchidism.

Results: In this study, occurrence took place more often on the right testicle (59.5\%), more frequently displaying inguinal localisation (59.5\%) and unilateral occurrence (70\%). Regarding bilateral presentation, the symmetrical form was the most common (86.8\%). Cryptorchidism was more common in the inguinal region of dog of small sized breeds and in the abdominal region in dogs of medium- and large-sized breeds.

Conclusions: Ultrasound scan proved a valuable diagnosis tool for cryptorchid testes, giving precise localisation and parenchymal changes thus leading to a safe clinical treatment. (Folia Morphol 2019; 78, 4: 847-852)

Key words: cryptorchidism, dog, prevalence, testicle, ultrasound scanning 


\section{INTRODUCTION}

Cryptorchidism (cryptorchismus) is defined as the non-descent of one or both testes to their normal anatomical position in the scrotum and is considered the most common congenital testicular alteration in dogs and man, displaying high occurrence rates in some breeds, mainly in the small sized and purebreds $[3,4,7,10,13,26,27]$.

Despite a wide range of studies in mammalian models, not all aspects of the hormonal control of testicular descent are fully understood [16]. The role of androgens in gubernacular development and the target(s) of androgen action in testicular descent remain controversial. Hutson et al. [8] reported absence of androgen receptor expression within the foetal gubernaculum and hypothesized that prenatal androgens act indirectly via masculinisation of the genitofemoral nerve. Nation et al. [17], Su et al. [25] proposed that androgens exert indirect effects on tissues extrinsic to the gubernaculum, including stimulation of androgen receptor-expressing cells in the inguinoscrotal fat pad and repression of the mammary branch of the genitofemoral nerve [17, 25]. In contrast, other investigators have observed androgen receptor expression in foetal rodent gubernacular mesenchyme [24].

The main theories explaining cryptorchidism in dogs are based on anatomical changes of the testicular gubernaculum which has an important role in the dilatation of the inguinal canal and directs the arrival of the testicle in the scrotum [12, 22].

Many studies have shown cryptorchidism in dogs during castration surgery $[12,27]$ but ultrasound scanning studies of prevalence are scarce in the literature.

Since only limited effort has been put in larger scale studies on cryptorchidism in dogs, it is not surprising that there is no clarity about the genetic basis of cryptorchidism. The role of environmental factors affecting testicular descent in dogs and human is not yet clear, as only few studies are available [11, 15, 26].

The purpose of this study was to use ultrasound scans to verify the prevalence of cryptorchidism in dogs and obtain data on testes localisation (inguinal or abdominal), occurrence, (unilateral or bilateral), and the most commonly affected sizes and breeds.

\section{MATERIALS AND METHODS}

From November, 1994 to March, 2007, 4924 dogs with ages from 3 months to 17 years were referred to the Centre for Veterinarian Diagnosis and Support
(Centro de Apoio e Diagnóstico Veterinário - CAD), Rio de Janeiro, Brazil, for ultrasound evaluation. These animals were divided in three groups according to their size. The small size group included dogs up to $10 \mathrm{~kg}$ of body weight, the mid-size group of dogs from $10.1 \mathrm{~kg}$ to $25 \mathrm{~kg}$ body weight and the large size group dogs above $25.1 \mathrm{~kg}$ body weight.

The ultrasound scans were carried out according to the standard techniques, with patients submitted to preparatory procedures, 8-h fast and adequate vesical repletion. Exams were carried out with patients in dorsal and lateral decubitus by execution of a trichotomy of the region to be visualised (abdominal and inguinal) and pasting an acoustic gel in order to obtain transversal, sagittal and oblique scans. Equipment set to real time B-mode (Aloka SSD 500 and SSD 900 - Aloka Co. Ltd., Tokyo, Japan), 5.0 MHz convex and 7.5 MHz micro-linear electronic transducers. Images were printed with a laser printer (Video Graphic Printer UP 870 MD, Sony Corporation, Tokyo, Japan) with specific purpose paper (Sony-Type IV - UPP - 110 HA, Sony Corporation, Tokyo, Japan).

Age, breed, testicle localisation (abdominal or inguinal), side of occurrence (right or left) and occurrence of unilateral or bilateral cryptorchidism of every canine were evaluated and recorded in medical cards. Bilateral cryptorchidism was subdivided into symmetrical and asymmetrical, that is, with both testes in the same or in different positions.

\section{Statistical analysis}

The $\chi^{2}$ test was used to analyse whether region and side of occurrence association was the same for dogs in the three size groups. Where a three variable table was used, the Cochran-Mantel-Haenszel Test (Agresti [1]) with a 5\% significance level was adopted.

For each breed group the Tukey Test (Zar [28]) was used to evaluate whether cryptorchidism propensity is the same for the various breeds.

\section{RESULTS}

Of the 4924 male dogs evaluated by ultrasound scanning, 403 were shown cryptorchid (8.2\%), representing 37 different breeds, where 377 (93.5\%) animals were of a pure and $26(6.5 \%)$ of undefined breeds (mix-breed dogs). Cryptorchidism was more prevalent in the following breeds: toy poodle, Yorkshire terrier, miniature pinscher, cocker spaniel, boxer, German shepherd, standard dachshund, beagle and Siberian husky (Table 1). 
Table 1. Dogs with ultrasound scan cryptorchidism diagnosis in a population of 4924 male dogs evaluated from 1994 to 2007 at the Centre for Veterinarian Diagnosis and Support (Centro de Apoio e Diagnóstico Veterinário - CAD), Rio de Janeiro, Brazil

\begin{tabular}{|c|c|c|c|}
\hline Breed & $\begin{array}{l}\text { Total number } \\
\text { of dogs }\end{array}$ & $\begin{array}{c}\text { Number of } \\
\text { cryptorchid dogs }\end{array}$ & $\begin{array}{l}\text { Per } \\
\text { cent }\end{array}$ \\
\hline \multicolumn{4}{|l|}{ Small breed } \\
\hline Bichon frisé & 61 & 4 & 0.08 \\
\hline Chihuahua & 10 & 3 & 0.06 \\
\hline Brazilian terrier & 34 & 4 & 0.08 \\
\hline Brussels griffon & 1 & 1 & 0.02 \\
\hline Lhasa apso & 43 & 1 & 0.02 \\
\hline Pomeranian & 11 & 3 & 0.06 \\
\hline Maltese & 40 & 5 & 0.1 \\
\hline Pekingese & 21 & 1 & 0.02 \\
\hline Pinscher & 159 & 23 & 0.46 \\
\hline Poodle & 1191 & 189 & 3.8 \\
\hline Pug & 14 & 5 & 0.1 \\
\hline Shih tzu & 24 & 5 & 0.1 \\
\hline Dachshund & 208 & 9 & 0.18 \\
\hline West H W terrier & 11 & 3 & 0.06 \\
\hline Whippet & 4 & 1 & 0.02 \\
\hline Yorkshire terrier & 299 & 27 & 0.54 \\
\hline \multicolumn{4}{|l|}{ Median breed } \\
\hline Beagle & 168 & 7 & 0.14 \\
\hline Bulldog & 17 & 2 & 0.04 \\
\hline Chow chow & 11 & 1 & 0.02 \\
\hline Cocker spaniel & 369 & 20 & 0.4 \\
\hline Mongrel Dog & 991 & 26 & 0.52 \\
\hline Schnauzer & 80 & 5 & 0.1 \\
\hline Shar-pei & 20 & 1 & 0.02 \\
\hline \multicolumn{4}{|l|}{ Big breed } \\
\hline Akita & 10 & 2 & 0.04 \\
\hline Boxer & 120 & 19 & 0.38 \\
\hline Collie & 18 & 2 & 0.04 \\
\hline Dalmatian & 27 & 1 & 0.02 \\
\hline Doberman & 56 & 1 & 0.02 \\
\hline Dogue de Bordeaux & 2 & 1 & 0.02 \\
\hline Fila Brasileiro & 50 & 2 & 0.04 \\
\hline Golden retriever & 21 & 1 & 0.02 \\
\hline Siberian husky & 98 & 7 & 0.14 \\
\hline Labrador retriever & 94 & 4 & 0.08 \\
\hline Old English sheepdog & 14 & 2 & 0.04 \\
\hline German shepherd & 235 & 11 & 0.22 \\
\hline Pit bull & 29 & 2 & 0.04 \\
\hline Weimaraner & 26 & 2 & 0.04 \\
\hline Other* & 337 & 0 & 0 \\
\hline Total & 4924 & 403 & \\
\hline
\end{tabular}

*0ther — breeds that showed no cryptorchidism

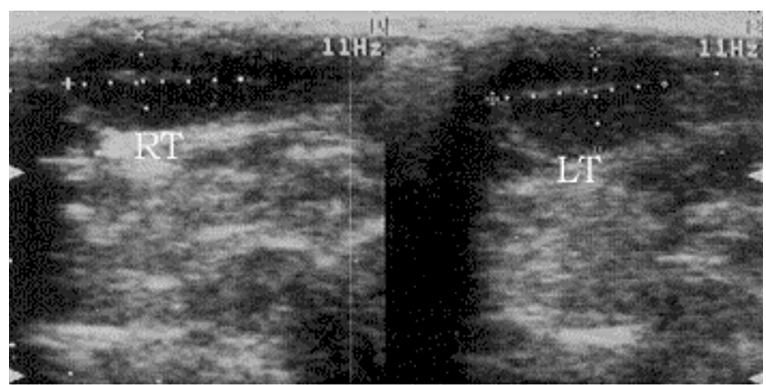

Figure 1. Ultrasound scan of bilateral inguinal cryptorchidism of a 3-year-old toy poodle dog; RT — right testicle; LT — left testicle.

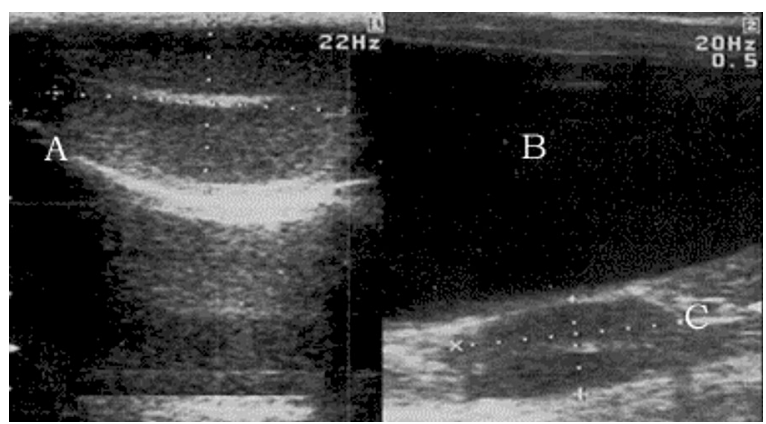

Figure 2. Ultrasound scan of a normal topic left-side testicle (A). Ultrasound scan of a normal aspect lateral to the bladder (B) abdominal cryptorchid testicle (C) of a 3-year-old cocker spaniel.

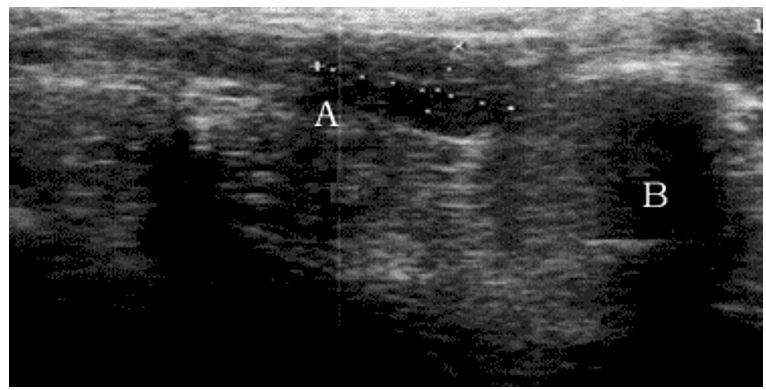

Figure 3. Right-side testicle $(A)$ in an abdominal localisation cranial to the prostate $(B)$ of a 3-year-old poodle.

Ultrasound scanning revealed the presence of cryptorchid testicles in an inguinal localisation, visualised in the subcutaneous corresponding to the inguinal region, and in abdominal localisation, observed caudal to the kidney, cranial and lateral to the bladder and cranial to the prostate (Figs. 1-3).

Cryptorchidism occurred mostly on the small size group, $284(70.5 \%)$ animals, with greatest prevalence for toy poodle, miniature pinscher and standard dachshund breeds. 
The mid-size group had 62 (15.4\%) dogs with no interbreed statistical difference perceived.

The large size group included 57 (14.1\%) animals where cryptorchidism prevalence was greatest for boxer and German shepherd breeds.

Unilateral cryptorchidism was the most prevalent, occurring in $282(70 \%)$ dogs, independently of size. Bilateral occurrence was present in $121(30 \%)$ dogs, with 105 (86.8\%) showing symmetry and 16 (13.2\%) asymmetry. The greatest prevalence of bilateral cryptorchidism occurred in the inguinal region with 68 (56.2\%) testes cryptorchid.

Right-side cryptorchidism and inguinal region showed a higher prevalence, respectively with $59.5 \%$ and $61.6 \%$ independently of animal size. Right-side inguinal presentation showed the greatest prevalence 190 (36.2\%), followed by left-size inguinal 133 (25.4\%), right-side abdominal, 122 (23.3\%), and left-size abdominal, 79 (15.1\%) (Table 2).

Relating cryptorchidism localisation to the size of the dog, a greater localisation in the inguinal region $(52.9 \%)$ was found for the small-size groups (52.9\%) and, for the mid-size and large size groups, the largest numbers, $8.2 \%$ and $11.4 \%$, respectively, were for the abdominal localisation (Table 3).

Regarding unilateral cryptorchidism, right-size inguinal localisation was the most prevalent in the small size group (31.3\%) and the right-side abdominal localisation in the mid-size group (4.8\%), no difference occurring between right- and left-size localisation for the large size group.

Inguinal bilateral cryptorchidism had a greater prevalence in small size dogs (59\%) and abdominal bilateral cryptorchidism in the mid and large size groups (respectively, $7.6 \%$ and $14.3 \%$ ).

Asymmetrical bilateral cryptorchidism had a $13.2 \%$ occurrence. Of these cases, $62.5 \%$ were right-side abdominal and left-side inguinal and $37.5 \%$ were rightside inguinal and left-side abdominal. As for breeds, bichon frise had 1 case, cocker spaniel -1 , Pekingese -1 , standard dachshund -1 , miniature pinscher -2 , Yorkshire terrier -2 , and toy poodle -16 .

\section{DISCUSSION}

Some authors $[2,13,14]$ focused on the detailed differences in the phenotypic expression of cryptorchidism and considered the disorder as the common phenotypic end result of a multiplicity of different genetic and non-genetic disorders.
Table 2. Number of cryptorchid testes by localisation and affected side and independent of animal size

\begin{tabular}{lccc}
\hline & Right & Left & Total \\
\hline Abdominal & $122(23.3 \%)$ & $79(15.1 \%)$ & $201(38.4 \%)$ \\
Inguinal & $190(36.2 \%)$ & $133(25.4 \%)$ & $323(61.6 \%)$ \\
Total & $312(59.5 \%)$ & $212(40.5 \%)$ & $524(100 \%)$ \\
\hline
\end{tabular}

Table 3. Cryptorchid testes as a function of animal size, region and affected size

\begin{tabular}{lccccc}
\hline Size group & \multicolumn{2}{c}{ Abdominal } & & \multicolumn{2}{c}{ Inguinal } \\
\cline { 2 - 3 } \cline { 5 - 6 } & Right & Left & & Right & Left \\
\hline Small & $67(12.8 \%)$ & $31(5.9 \%)$ & & $164(31.3 \%)$ & $113(21.6 \%)$ \\
Mid & $25(4.8 \%)$ & $18(3.4 \%)$ & & $20(3.8 \%)$ & $13(2.5 \%)$ \\
Large & $30(5.7 \%)$ & $30(5.7 \%)$ & & $6(1.1 \%)$ & $7(1.3 \%)$ \\
Total & $122(23.3 \%)$ & $79(15.1 \%)$ & & $190(36.2 \%)$ & $133(25.4 \%)$ \\
\hline
\end{tabular}

Dog testicular migration is influenced by foetal testicle androgen secretion around the $54^{\text {th }}$ day of pregnancy $[13,22]$. At birth, the dog's testicle is near the inner ring of the inguinal canal and crossing the inguinal canal in about 5 days. Migration is complete from the sixth to the eighth week after birth $[13,22]$.

In dogs, cryptorchidism is frequent and previous reports show rates in the range of $0.8 \%$ to $15 \%$ $[14,20,21,23,27]$.

Cryptorchidism prevalence variations described in literature are related to the breeds in the population under study, a greater frequency being shown by purebred dogs $[4,7,19,20,27]$. Most (3.933) animals in the current study were pure breeds which seems to explain the $8.2 \%$ cryptorchidism prevalence found.

The $0.52 \%$ prevalence in the mix-breed dogs was different to the 3.9\% found by Yates et al. [27] and the $6.6 \%$ by Ortega-Pacheco et al. [18]. Such discrepancy can be a result of the predominantly mongrel dog population used by the latter.

In terms of breeds, the highest cryptorchidism prevalence were seen in toy poodle, Yorkshire terrier, boxer, German shepherd, standard dachshund and Siberian husky, results similar to those reported in the literature $[7,19,27,29]$.

Mix-breed dogs $(0.52 \%)$ as well as miniature pinschers $(0.46 \%)$, cocker spaniels $(0.4 \%)$ and beagles $(0.14 \%)$ showed important values of cryptorchidism in this study, however reports were found that showed them as a low risk factor for such disturbance $[7,19]$. 
Though many authors have reported cryptorchidism as occurring mainly in small dogs $[7,19,20,27]$, only Batista Arteaga et al [4] describe values (57\%) lower than the $70.5 \%$ in their study. It is believed that this high prevalence of cryptorchidism in this size range can be explained by a difference between the testicle size and the inguinal canal hampering testicular descent $[7,19]$.

Corroborating data in the literature, cryptorchidism was found to be more frequent on the rightside testicle, which can be associated to the longer distance to be covered by the right testicle in its descent due to its more cranial position in the abdomen $[4-7,21,27]$.

In this study, small and mid-size groups showed a greater occurrence of right-side cryptorchidism and in the large size group right- and left-side cryptorchidism were similar, agreeing with Batista Arteaga et al. [4].

Concerning the greatest prevalence in unilateral cryptorchidism, results herein agree with the findings of Reif and Brodey [21], Hayes et al. [7], Batista Arteaga et al. [4], Yates et al. [27] and Ortega-Pacheco et al. [18].

Inguinal cryptorchidism observation had a greater prevalence in this study, agreeing closely to the findings of Batista Arteaga et al. [4] and Yates et al. [27] but disagreeing with those of Reif and Brodey [21], Cox et al. [5], Ortega-Pacheco et al. [18] and Felumlee et al. [6] which report a higher prevalence of abdominal cryptorchidism.

Evaluation of results as a function of the size of the animal showed a greater prevalence of abdominal cryptorchidism in the mid- and large-size groups and inguinal cryptorchidism in the small size group, agreeing with Batista Arteaga et al. [4] that describes a greater prevalence of inguinal cryptorchidism in midand small-size dogs, finding no differences between abdominal and inguinal prevalence in large dogs.

Right-size inguinal localisation was the most frequent and asymmetrical bilateral localisation with testes in the right inguinal and left abdominal regions the least frequent in Yates et al. [27], which agrees with our results. However, the second most common localisation found in our population was the left side inguinal, disagreeing with Yates et al. [27] that reports right side abdominal as the second most frequent one.

As with Yates et al. [27], animals studied herein showed bilateral symmetrical cryptorchidism to be more common than the bilateral asymmetrical variant.

All localisation data for the ectopic testicles was obtained from ultrasound scans which contributed significantly to a more accurate diagnosis, revealing localisation and changes in the parenchyma of palpable and non-palpable testes.

Cryptorchidism is a disorder that influences the development of affected individuals from an early embryological stage on, so it may have physiological and numerical consequences at all levels of the reproductive process. It even might influence conception rates. Further detailed studies are needed to evaluate the effects of cryptorchidism on the pre-weaning part of life. It is a disorder with a variable phenotypic expression: unilateral versus bilateral, and variability in the location of the retained testicle(s).

This kind of cryptorchidism prevalence studies on different breeds and size of dogs is also important since it can be used as an experimental model for the study of human cryptorchidism [9].

\section{CONCLUSIONS}

Canine cryptorchidism prevalence in our sample was $8.2 \%$ and the mainly affected breeds were boxer, German shepherd, miniature pinscher, toy poodle and standard dachshund.

The animal most affected were the ones in the small size group. Regardless of size, right-side testicles were the most frequently affected.

Unilateral presentation predominated. Among the bilateral forms symmetrical cryptorchidism was the most prevalent in all groups. Inguinal localisations were most prevalent in small size dogs while abdominal localisations predominated in mid- and large-size animals. Ultrasound scanning proved adequate to diagnosis, localisation and change detection in cryptorchid testes.

\section{Acknowledgements}

We are grateful to Dr. Cesar Augusto Taconeli from Statistical Department - UNESP for assistance with statistical analysis. The authors are also thankful to Centro de Apoio e Diagnóstico Veterinário - CAD, Rio de Janeiro, Brazil. Conselho Nacional de Desenvolvimento Científico e Tecnológico (CNPq), Fundação de Amparo à Pesquisa do Estado do Rio de Janeiro (FAPERJ) and the Coordenação de Aperfeiçoamento de Pessoal de Nível Superior (CAPES). 


\section{REFERENCES}

1. Agresti A. An introduction to categorical data analysis. New York 1996: 16-70.

2. Amann RP, Veeramachaneni DNR. Cryptorchidism and Associated Problems in Animals 2006: 13.

3. Barthold JS, Reinhardt S, Thorup J. Genetic, Maternal, and Environmental Risk Factors for Cryptorchidism: An Update. Eur J Pediatr Surg. 2016; 26(5): 399-408, doi: 10.1055/s0036-1592416, indexed in Pubmed: 27642851.

4. Batista Arteaga M, Gonzalez Valle F, Cabrera Martin F, et al. Morphologic and endocrinologic characteristics of retained canine testes. Canine Practice. 2000; 25(3): 12-15.

5. Cox VS, Wallace $\sqcup$, Jessen $C R$. An anatomic and genetic study of canine cryptorchidism. Teratology. 1978; 18(2): 233-240, doi: 10.1002/tera.1420180208, indexed in Pubmed: 31014.

6. Felumlee $A E$, Reichle JK, Hecht $\mathrm{S}$, et al. Use of ultrasound to locate retained testes in dogs and cats. Vet Radiol Ultrasound. 2012; 53(5): 581-585, doi: 10.1111/j.17408261.2011.01943.x, indexed in Pubmed: 22731857.

7. Hayes HM, Wilson GP, Pendergrass TW, et al. Canine cryptorchism and subsequent testicular neoplasia: case-control study with epidemiologic update. Teratology. 1985; 32(1): 51-56, doi: 10.1002/tera.1420320108, indexed in Pubmed: 2863879.

8. Hutson JM, Li R, Southwell BR, et al. Regulation of testicular descent. Pediatr Surg Int. 2015; 31(4): 317-325, doi: 10.1007/s00383-015-3673-4, indexed in Pubmed: 25690562.

9. Hutson JM, Li R, Vikraman J, et al. What animal models of testicular descent and germ cell maturation tell us about the mechanism in humans. Eur J Pediatr Surg. 2016; 26(5): 390-398, doi: 10.1055/s-0036-1592196, indexed in Pubmed: 27649393.

10. Hutson JM, Southwell BR, Li R, et al. The regulation of testicular descent and the effects of cryptorchidism. Endocr Rev. 2013; 34(5): 725-752, doi: 10.1210/er.2012-1089, indexed in Pubmed: 23666148.

11. Jørgensen KT, Jensen MS, Toft GV, et al. Risk of cryptorchidism and hypospadias among boys of maternal hairdressers - a Danish population-based cohort study. Scand J Work Environ Health. 2013; 39(3): 302-309, doi: 10.5271/ sjweh.3330, indexed in Pubmed: 23111987.

12. Kersten W, Molenaar GJ, Emmen JM. Bilateral cryptorchidism in a dog with persistent cranial testis suspensory ligaments and inverted gubernacula: report of a case with implications for understanding normal and aberrant testis descent. J Anat. 1996; 189(Pt 1): 171-176.

13. Khan FA, Gartley CJ, Khanam A. Canine cryptorchidism: An update. Reprod Domest Anim. 2018; 53(6): 1263-1270, doi: 10.1111/rda.13231, indexed in Pubmed: 29956390.

14. Lea RG, Byers AS, Sumner RN, et al. Environmental chemicals impact dog semen quality in vitro and may be associated with a temporal decline in sperm motility and increased cryptorchidism. Sci Rep. 2016; 6: 31281, doi: 10.1038/srep31281, indexed in Pubmed: 27503122.

15. Lee PA, Houk CP. Cryptorchidism. Curr Opin Endocrinol Diabetes Obes. 2013; 20(3): 210-216, doi: 10.1097/ MED.0b013e32835ffc7d, indexed in Pubmed: 23493040.
16. Morgan JT, Robbins AK, Mateson AB, et al. Regional Variation in Androgen Receptor Expression and Biomechanical Properties May Contribute to Cryptorchidism Susceptibility in the LE/orl Rat. Front Endocrinol (Lausanne). 2018; 9: 738, doi: 10.3389/fendo.2018.00738, indexed in Pubmed: 30568634 .

17. Nation $T$, Balic $A$, Buraundi $S$, et al. The antiandrogen flutamide perturbs inguinoscrotal testicular descent in the rat and suggests a link with mammary development. J Pediatr Surg. 2009; 44(12): 2330-2334, doi: 10.1016/j. jpedsurg.2009.07.072, indexed in Pubmed: 20006020.

18. Ortega-Pacheco A, Rodríguez-Buenfil JC, Segura-Correa JC, et al. Pathological conditions of the reproductive organs of male stray dogs in the tropics: prevalence, risk factors, morphological findings and testosterone concentrations. Reprod Domest Anim. 2006; 41(5): 429-437, doi: 10.1111/j.1439-0531.2006.00688.x, indexed in Pubmed: 16984349.

19. Pendergrass TW, Hayes HM. Cryptorchism and related defects in dogs: epidemiologic comparisons with man. Teratology. 1975; 12(1): 51-55, doi: 10.1002/ tera.1420120107, indexed in Pubmed: 240213.

20. Priester WA, Glass AG, Waggoner NS. Congenital defects in domesticated animals: general considerations. Am J Vet Res. 1970; 31(10): 1871-1879, indexed in Pubmed: 5528341.

21. Reif JS, Brodey RS. The relationship between cryptorchidism and canine testicular neoplasia. J Am Vet Med Assoc. 1969; 155(12): 2005-2010, indexed in Pubmed: 4391618.

22. Romagnoli SE. Canine cryptorchidism. Vet Clin North Am Small Anim Pract. 1991; 21(3): 533-544, indexed in Pubmed: 1677504.

23. Ruble RP, Hird DW. Congenital abnormalities in immature dogs from a pet store: 253 cases (1987-1988). J Am Vet Med Assoc. 1993; 202(4): 633-636, indexed in Pubmed: 8095494.

24. Staub $C$, Rauch $M$, Ferrière $F$, et al. Expression of estrogen receptor ESR1 and its 46-kDa variant in the gubernaculum testis. Biol Reprod. 2005; 73(4): 703-712, doi: 10.1095/ biolreprod.105.042796, indexed in Pubmed: 15944240.

25. Su S, Farmer PJ, Li R, et al. Regression of the mammary branch of the genitofemoral nerve may be necessary for testicular descent in rats. J Urol. 2012; 188(4 Suppl): 1443-1448, doi: 10.1016/j.juro.2012.02.041, indexed in Pubmed: 22906642.

26. Thonneau PF, Gandia P, Mieusset R, et al. Cryptorchidism: incidence, risk factors, and potential role of environment; an update. J Androl. 2003; 24(2): 155-162, indexed in Pubmed: 12634298.

27. Yates $D$, Hayes $G$, Heffernan $M$, et al. Incidence of cryptorchidism in dogs and cats. Vet Rec. 2003; 152(16): 502-504, doi: 10.1136/vr.152.16.502, indexed in Pubmed: 12733559.

28. Zar J. Biostatistical analysis. 4th Ed., New Jersey 1999: 563-565.

29. Zhao X, Du ZQ, Rothschild MF. An association study of 20 candidate genes with cryptorchidism in Siberian Husky dogs. J Anim Breed Genet. 2010; 127(4): 327-331, doi: 10.1111/j.1439-0388.2010.00859.x, indexed in Pubmed: 20646120. 